\title{
Maternal satisfaction on delivery care services and associated factors among mothers who gave birth in the University of Gondar teaching and referral hospital, northwest Ethiopia
}

\author{
Andualem Firdie \\ University of Gondar \\ Alemnew Maru \\ University of Gondar \\ Abdulahi Deriye \\ University of Gondar \\ Amare Assefa \\ University of Gondar \\ Abdi Bedassa \\ University of Gondar \\ Anteneh Bekele \\ University of Gondar \\ Amanuel Alemayehu \\ University of Gondar \\ Zegeye Abebe \\ University of Gondar \\ Zemichael Gizaw ( $\nabla$ zemichael12@gmail.com ) \\ University of Gondar https://orcid.org/0000-0002-6713-1975
}

Research article

Keywords: Maternal satisfaction, delivery care services, University of Gondar teaching and referral hospital

Posted Date: July 17th, 2019

DOI: https://doi.org/10.21203/rs.2.11479/v1

License: (c) (1) This work is licensed under a Creative Commons Attribution 4.0 International License.

Read Full License 


\section{Abstract}

Introduction Maternal satisfaction on delivery services is an important indicator for assessment of the quality of care. Quality of delivery care increases the likelihood of timely and appropriate treatment and good outcomes. The use of delivery services and outcomes are the result not only of the provision of care but also of women's experience of that care. Therefore, investigating women's experience or satisfaction on delivery care is of paramount importance to enhance the services utilization. Methods An institutionbased cross-sectional study design was used. Data were collected using structured and pretested questionnaire from 403 mothers who were recruited by simple random sampling technique. Multivariable binary logistic regression analysis was used to identify variables associated with maternal satisfaction on delivery services on the basis of adjusted odds ratio (AOR) with $95 \%$ confidence interval $(\mathrm{Cl})$ and a pvalue less than 0.05 . Results The current study found that the overall satisfaction of mothers on delivery services was found to be $65.5 \%$. Specifically, $78.2 \%, 65.5 \%, 64.3 \%, 49.9 \%$ and $44.7 \%$ of the mothers who gave birth at the University of Gondar teaching and referral hospital were satisfied on physicians' communication, healthcare services, physicians' attitude, privacy and sanitation condition of the health institution respectively. Maternal satisfaction was statistically associated with maternal education (diploma and above education) $[\mathrm{AOR}=0.29,95 \% \mathrm{Cl}=(0.13,0.66)]$, maternal education (secondary and/or primary education) $[\mathrm{AOR}=0.42,95 \% \mathrm{Cl}=(0.20,0.90)]$, antenatal care (ANC) follow-up in the current pregnancy $[A O R=4.47,95 \% \mathrm{Cl}=(1.77,11.27)]$ and short waiting time $[A O R=1.85,95 \% \mathrm{Cl}=(1.19,2.88)]$. Conclusion This study revealed that the overall satisfaction of mothers on delivery service was found to be suboptimal. Physicians' communication, healthcare services and physicians' attitude were areas where the highest proportion of mothers satisfied. On the other hand, the highest proportion of mothers was dissatisfied on sanitation condition. Educational status, ANC follow-up and waiting time were found to be statistically associated with maternal satisfaction on delivery services.

\section{Background}

Maternal satisfaction on delivery services is an important indicator for assessment of the quality of care. Quality of delivery care is the degree to which maternal health services for individuals and populations increases the likelihood of timely and appropriate treatment for the purpose of achieving desired outcomes. The use of services and outcomes are the result not only of the provision of care but also of women's experience of that care(1).

The quality of maternity care received by mothers in developing countries is often reported as poor. Poor quality of maternity care leads to maternal and child death. Globally, about 800 women die from pregnancy or labor related complications every day. In 2010, around 287,000 women died during pregnancy and childbirth(2). The maternal mortality is reported to be 14 times higher in developing regions than the developed(3). Sub-Saharan Africa alone accounted for $62 \%$ of global maternal deaths. Maternal mortality in the Sub-Saharan Africa region is reaching 686 per 100,000 live births(2). The lifetime risk of maternal death in industrialized countries is 1 in 4,000 vs. 1 in 51 in countries classified as 'least developed'(4). 
Ethiopia is one of ten countries sharing $58 \%$ of the global maternal deaths reported in 2013 (3) and has an maternal mortality rate of 412 per 100,000 live births(5). According to Ethiopian demographic and health surveys (EDHS) 2016, institutional delivery was $26 \%$ which is low. One possible reason for this low institutional delivery might include unhappy health institutional delivery experience for the mother that limits their ability to utilize the service in subsequent pregnancies. Factors might include low ANC coverage, gender sensitivity, preservation of dignity, and cultural sensitivity(6-10).

Ensuring client satisfaction is an important means of secondary prevention of mortality. Satisfied patients are more likely to utilize health services, comply with medical treatment, and continue to interact with healthcare providers(11). When patients are satisfied, medical management and outcomes are enhanced. Patient satisfaction is a measure of the quality of care and is indispensable for the assessment of quality and the design and management of healthcare systems(1214). Assessing client satisfaction with respect to service delivery and the healthcare facilities might help guide the development and improvement of service delivery. This institution-based cross-sectional study was, therefore, conducted to assess level of satisfaction on delivery care services among mothers who gave birth at the University of Gondar teaching and referral hospital.

\section{Methods}

\section{Study design and period}

An institution based cross-sectional study design was used to assess level of maternal satisfaction on delivery care service and associated factors among mothers who gave birth in University of Gondar teaching and referral hospital during September 2017.

\section{Sample size determination and sampling procedures}

Sample size was determined using single population proportion formula with the following assumptions: maternal satisfaction on labor and delivery care services in referral hospitals $=61.9 \%(15), 95 \%$ confidence interval, $5 \%$ marigion of error and $15 \%$ nonresponse rate. The estimated sample size was thus 418 women. Simple random sampling technique was used to select the study subject using the registeration book as a sampling frame.

\section{Data collection procedure}

Data were collected using structured and pretested questionnaire (see supplementary file). Data were collected by final year medical students. Trainng on techniques of face to face interview and research ethics was given to data collectors. The interview were done when the mothers were about to be discharged from the labor and delivery wards.

\section{Measurment of outcome variable}


Mothers' satisfaction on labor and delivery care services, the primary outcome variable of this study was measured using a five scale (very dissatisfied, dissatisfied, neutral, satisfied, and very satisfied) assessment tool. Point 1 was given for very dissatisfied, 2 for dissatisfied, 3 for neutral, 4 for satisfied and 5 for very satisfied. The answer of each question was summed-up and dvided by the total number of questions and then multiplied by 100 to determine level of satisfaction. Accordingly, mothers' satisfaction was taken as 'satisfied' if mothers scored $75 \%$ and above points and 'dissatisfied' if they scored less than $75 \%(15,16)$.

\section{Data analysis}

Data were entered to Epi-Infor version seven and exported to statistical package for social sciences (SPSS) version twenty for analysis. Descriptive statistics, like mean, standard deviation, frequency, and percent were analysed for most variables. Univariable binary logistic regression analysis was used to select variables for the multivariable binary logistic regression analysis on the basis of a p-value less than 0.2 . Variables having a $p$-value less than 0.2 by the univariable analysis were further analysed by multivariable binary logistic regression to control confounding and finally variables associated with mothers' satisfaction were identified on the basis of AOR with $95 \% \mathrm{Cl}$ and a $\mathrm{p}$ - value less than 0.05 .

\section{Results}

\section{Sociodemographic characterstics of participants}

A total of 403 postnatal mothers participated in this study with $96.4 \%$ response rate. Among these mothers, 274 (68\%) were from urban. Two hundred seven (51.4\%) of the mothers were aged between 25 and 34 years. The mean age was 28 years $( \pm 6$ SD). Almost all, $388(96.3 \%)$ of the mothers were engaged at the time of the survey. Three hundred thirty-nine (84.1\%) mothers were at least can read and write. Ninety-five $(23.6 \%)$ mothers were housewife by their occupation. Eighty-five $(21.1 \%)$ of the mothers were from a family of greater than five members. Twenty-three $(5.7 \%)$ of the mothers gave more than five births(Table 1).

\section{ANC related information}

The majority, 383 (95\%) of mothers knew about ANC and 373 (92.6\%) of the mothers had access to ANC care services. Three hundred seventy-two (92.3\%) of the mothers who gave birth were at ANC follow-up for the current pregnancy. Two hundred nineteen (58.9\%) of the mother who had ANC follow-up for the current pregnancy got the services from University of Gondar teaching and referral hospital and 206 $(55.4 \%)$ of the mothers reported that each visit took more than twenty minutes. One hundred fifty-five $(41.7 \%)$ of the mothers followed more than four times (Table 2).

\section{Labor and delivery related services}

The vast majority, $318(85 \%)$ of the mothers deliverd their previous baby through spontaneous vaginal delivery (SVD) and $230(57.1 \%)$ of the mothers reported that they gave birth at hospitals for their previous 
pregnancy. Two hundred ten (52.1\%) mothers came to hospital by their own plan. Two hundred fifteen (53.3\%) of the mothers reported that they waited for 10 or below minutes to get services. Three hundred eighty-seven (96\%) of the mothers were seen by doctors during delivery and the labor of 381 (94.5\%) mothers lasted more than 3 hours. Three hundred eighty(94.3\%) mothers gave alive birth and $76(18.9 \%)$ of the new borne babies were under weight (Table 3).

\section{Mothers' satisfaction on delivery care service}

Mothers' satisfaction on delivery care services was measured using 31 questions categorized under five categories (10 questions under healthcare services, 6 under physicians' communication, 5 under physicians' attitude, 4 under privacy, and 6 under sanitation categories). Time spend with healthcare service providers (379/94\%) and medical care received (377/93.5\%) were areas where the highest proportion of mothers satisfied under the healthcare service category(Figure 1). The way healthcare providers explain clients health condition (358/88.8\%), information about procedures(355/88.1\%) and care providers' devotion to listen clients' worry (355/83.6\%) were areas where the highest proportion of mothers satisfied under the physicians' communication category (Figure 2). Doctors' respection(363/90.1\%), nurses' respection(193/47.9\%) and the way staffs accept clients' opinion(193/47.9\%) were areas where the highest proportion of mothers satisfied under the physicians' attitude category (Figure 3). Availability of separate delivery/examination rooms(260/65.3\%) and gender mix of care providers (260/64.5\%) were areas where the highest proportion of mothers satisfied under the privacy category (Figure 4$)$. Cleanliness of facilities (279/69.2\%) and cleanliness of waiting areas $(256 / 63.5 \%)$ and were areas where the highest proportion of mothers satisfied under the sanitation category (Figure 5). Physicians' communication (315/78.2\%), healthcare services (264/65.5\%), and physicians' attitude (259/64.3\%) were areas where the highest proportion of mothers satisfied. On the other hand, the highest proportion of mothers $(223 / 55.3 \%)$ were dissatisfied on sanitation condition (Figure 6). Overall, 264 (65.5\%) of the mothers were satisfied on delivery services and the rest 139 (34.5\%) mothers were dissatisfied.

\section{Factors associated with mothers' level of satisfaction on delivery services}

Table 4 shows factors associated with mothers' level of satisfaction on delivery services. Level of maternal education, ANC follow-up in the current pregnancy, waiting time, qualification of care providers, duration of labor, and pregnancy outcomes were selected to the multivariable binary logistic regression analysis by the univariable binary logistic regression analysis. Maternal satisfaction on delivery was statistically associated with level of maternal education, ANC follow-up in the current pregnancy, and waiting time.

This study revealed that literate mothers were more dissatisfied than illiterate mothers. The odds of satisfaction was $71 \%$ less among mothers whose education level was diploma and above compared with mothers who didn't attend formal education $[A O R=0.29,95 \% \mathrm{Cl}=(0.13,0.66)]$. Mothers who attended secondary education and/or primary education were less likely to be satisfied compared with illiterate mothers[AOR $=0.42,95 \% \mathrm{Cl}=(0.20,0.90)]$. 
Maternal satisfaction on delivery services was significantly associated with ANC follow-up in the current pregnancy. The probability of being satisfied was 4.47 times more likely to be higher among mothers who had ANC follow-up compared with their counterparts [AOR $=4.47,95 \% \mathrm{Cl}=(1.77,11.27)]$.

The current study depicted that waiting time was associated with maternal satisfaction on delivery services. Mothers who waited for 10 and/or below minutes were 1.85 times more likely to be satisfied compared with mothers who waited for more than 10 minutes to get services [AOR $=1.85,95 \% \mathrm{Cl}=(1.19$, 2.88)].

\section{Discussion}

The present study determined the level of maternal satisfaction on delivery services at the University of Gondar teaching and referral hospital, northwest Ethiopia. The overall satisfaction level of mothers was found to be $65.5 \%(95 \% \mathrm{Cl}=60.1,70.2 \%)$. The current level of satisfaction was in line with the reports of other similar studies in Amhara region (61.9\%)(15) and South Ethiopia (67.9\%)(17). The level of maternal satisfaction reported in this study was lower than the findings of other similar studies in Debremarkos $(81.7 \%)(16)$, Assela (80.7\%)(18), Bure (88\%)(19), Bahir Dar(74.9 \%)(20), Hawassa (87.7\%)(21), Wolayta zone(82.9\%)(22), Arba Minch(90.2\%)(23) and Nepal(89.88\%)(24). The Current level of maternal satisfaction was also higher than the findings of other studies in Iran (59.5\%)(25) and Sri Lanka(29.6\%) (26). The difference in level of maternal satisfaction across studies might be due to variation in health institutions quality and healthcare providers competency, behavior and approach.

This study showed that education status of mothers was found to be significantly associated with maternal satisfaction on delivery care rervices. Mothers who attended formal education were dissatisfied. Other similar studies also reported the inverse relation of satisfaction and educational status of mothers $(18,19,21,23)$. The probable reason might be due to the fact that educated mothers expect and demand better healthcare service quality. Moreover, educated mothers might know service quality standards and might compare the services they received with the standards(24).

This institution-based cross-sectional study depicted that maternal satisfaction on delivery services was significantly associated with ANC follow-up which is inline with the findings of other studies $(\mathbf{1 5}, \mathbf{1 8}, \mathbf{2 3}$, 27). ANC follow-up might give mothers a continuum of care from the ante-natal to the post-partum period which will grant mothers all the necessary information about birth preparedness and information related to the current pregnancy(28).

This study found that waiting time to get healthcare service was the other statistically significant variable with maternal satisfaction. Mothers who waited shorter time to get service were more satisfied. This finding is also supported by other studies $(15,18,23)$. This might be due to the fact that providing healthcare services with no delay can prevent complication due to prolonged pain and clients boringness $(29,30)$. 


\section{Conclusions}

This study revealed that the overall satisfaction of mothers on delivery service was found to be suboptimal. Physicians' communication, healthcare services and physicians' attitude were areas where the highest proportion of mothers satisfied. On the other hand, the highest proportion of mothers was dissatisfied on sanitation condition. Educational status, ANC follow-up and waiting time were found to be statistically associated with maternal satisfaction.

\section{Abbreviations}

ANC: Antenatal care; AOR: Adjusted odds ratio; EDHS: Ethiopian demographic and health surveys; Cl: Confidence interval; CS: Caesarean section; SD: Standard deviation; SPSS: Statistical package for social sciences; SVD: Spontaneous vaginal delivery

\section{Declarations}

\section{Ethics approval and consent to participate}

Ethical clearance was obtained from the Institutional Review Board of the University of Gondar. There were no risks due to participation in this research. The collected data were used only for this research purpose. Verbal informed consent was obtained from the mothers. The information collected from participants kept with complete confidentiality. Privacy was maintained during the interview.

\section{Consent for publication}

This manuscript does not contain any individual person's data.

\section{Availability of data and material}

Data will be made available upon requesting the primary author.

\section{Competing Interest}

None of the authors have any competing interests in the manuscript.

\section{Funding information}

This study had no any special fund. However, the University of Gondar had covered questionnaire duplication fee.

\section{Authors' contribution}

$A F, A M, A D, A A, A B, A B$ and $A A$ participated during conception of the research issue, development of a research proposal and data collection. ZA supervise the data collection process and wrote various parts 
of the research report. ZG analyzed the data and prepared the manuscript. All the authors read and approved the final manuscript.

\section{Acknowledgment}

The authors are pleased to acknowledge data collectors, supervisors and study participants for their unreserved contributions to the success of this study. The authors are also pleased to acknowledge the University of Gondar for duplicating the questionnaire.

\section{References}

1. Van den Broek N, Graham W. Quality of care for maternal and newborn health: the neglected agenda. BJOG: An International Journal of Obstetrics \& Gynaecology. 2009;116:18-21.

2. Bongaarts J. WHO, UNICEF, UNFPA, World Bank Group, and United Nations Population Division Trends in Maternal Mortality: 1990 to 2015 Geneva: World Health Organization, 2015. Population and Development Review. 2016;42(4):726-.

3. WHO and Unicef. Trends in maternal mortality: 1990 to 2013: estimates by WHO, UNICEF, UNFPA, The World Bank and the United Nations Population Division: executive summary. World Health Organization, 2014. Available at http://apps.who.int/iris/bitstream/10665/112682/2/9789241507226_eng.pdf.

4. Ronsmans C, Graham WJ, group LMSSs. Maternal mortality: who, when, where, and why. The lancet. 2006;368(9542):1189-200.

5. Ethiopia Demographic and Health Survey 2016 - The DHS Program. Available at https://dhsprogram.com/pubs/pdf/FR328/FR328.pdf.

6. Worku AG, Yalew AW, Afework MF. Factors affecting utilization of skilled maternal care in Northwest Ethiopia: a multilevel analysis. BMC international health and human rights. 2013;13(1):20.

7. Mengesha ZB, Biks GA, Ayele TA, Tessema GA, Koye DN. Determinants of skilled attendance for delivery in Northwest Ethiopia: a community based nested case control study. BMC Public Health. 2013;13(1):130.

8. Teferra AS, Alemu FM, Woldeyohannes SM. Institutional delivery service utilization and associated factors among mothers who gave birth in the last 12 months in Sekela District, North West of Ethiopia: A community-based cross sectional study. BMC pregnancy and childbirth. 2012;12(1):74.

9. Amano A, Gebeyehu A, Birhanu Z. Institutional delivery service utilization in Munisa Woreda, South East Ethiopia: a community based cross-sectional study. BMC pregnancy and childbirth. 2012;12(1):105.

10. Abeje G, Azage M, Setegn T. Factors associated with Institutional delivery service utilization among mothers in Bahir Dar City administration, Amhara region: a community based cross sectional study. Reproductive Health. 2014;11(1):22. 
11. World Health Organization (WHO). Beyond the Numbers: Reviewing Maternal Deaths and Complications to Make Pregnancy Safer, 2004; Geneva, Switzerland. Available at http://www.who.int/maternal_child_adolescent/documents/9241591838/en/.

12. Al-Abri R, Al-Balushi A. Patient satisfaction survey as a tool towards quality improvement. Oman medical journal. 2014;29(1):3.

13. Patwardhan $\mathrm{A}$, Spencer $\mathrm{CH}$. Are patient surveys valuable as a service-improvement tool in health services? An overview. J Healthc Leadersh. 2012;4:33-46.

14. Sodani PR, Kumar RK, Srivastava J, Sharma L. Measuring patient satisfaction: A case study to improve quality of care at public health facilities. Indian journal of community medicine: official publication of Indian Association of Preventive \& Social Medicine. 2010;35(1):52.

15. Tayelgn A, Zegeye DT, Kebede Y. Mothers' satisfaction with referral hospital delivery service in Amhara Region, Ethiopia. BMC pregnancy and childbirth. 2011;11(1):78.

16. Bitew K, Ayichiluhm M, Yimam K. Maternal satisfaction on delivery service and its associated factors among mothers who gave birth in public health facilities of Debre Markos Town, Northwest Ethiopia. BioMed research international. 2015;2015.

17. Darebo TD, Abera M, Abdulahi M, Berheto TM. Factors Associated with Client Satisfaction with Institutional Delivery Care at Public Health Facilities in South Ethiopia. Journal of Medicine, Physiology and Biophysics 2016;25:19 - 28.

18. Amdemichael R, Tafa M, Fekadu H. Maternal satisfaction with the delivery services in Assela Hospital, Arsi Zone, Oromia Region, Ethiopia, 2013. Obstetrics \& Gynecology (Sunnyvale).4.

19. Asres GD. Satisfaction and Associated Factors among Mothers Delivered at Asrade Zewude Memorial Primary Hospital, Bure, West Gojjam, Amhara, Ethiopia: A Cross Sectional Study. International Research in Medical and Health Science. 2018;1(1):39-49.

20. Mekonnen ME, Yalew WA, Anteneh ZA. Women's satisfaction with childbirth care in Felege Hiwot Referral Hospital, Bahir Dar city, Northwest Ethiopia, 2014: cross sectional study. BMC research notes. 2015;8(1):528.

21. Agumasie M, Yohannes Z, Abegaz T. Maternal Satisfaction and Associated Factors on Delivery Care Service in Hawassa City Public Hospitals, South Ethiopia. Gynecology \& Obstetrics. 2018;8(5).

22. Yohannes $B$, Tarekegn $M$, Paulos $W$. Mothers' utilization of antenatal care and their satisfaction with delivery services in selected public health facilities of wolaita zone, Southern Ethiopia. International journal of scientific \& technology research. 2013;2(2):74-85.

23. Dewana Z, Fikadu T, Abdulahi M. Client perspective assessment of women's satisfaction towards labour and delivery care service in public health facilities at Arba Minch town and the surrounding district, Gamo Gofa zone, south Ethiopia. Reproductive health. 2016;13(1):11.

24. Panth A, Kafle P. Maternal Satisfaction on Delivery Service among Postnatal Mothers in a Government Hospital, Mid-Western Nepal. Obstetrics and gynecology international. 2018;2018.

25. Taghavi S, Ghojazadeh M, Azami-Aghdash S, Alikhah H, Bakhtiarzadeh K, Azami A, et al. Assessment of mothers' satisfaction with the care of maternal care in Specialized Educational-Medical Centers in 
obstetrics and gynecological disease in Northwest, Iran. Journal of Analytical Research in Clinical Medicine. 2015;3(2):77-86.

26. Senarath U, Fernando DN, Rodrigo I. Factors determining client satisfaction with hospital-based perinatal care in Sri Lanka. Tropical Medicine \& International Health. 2006;11(9):1442-51.

27. Tadesse BH, Bayou NB, Nebeb GT. Mothers' Satisfaction with Institutional Delivery Service in Public Health Facilities of Omo Nada District, Jimma Zone Clinical Medicine Research. 2017;6(1):23-30.

28. World Health Organization (WHO). Essential Antenatal, Perinatal and Postpartum Care Training modules. WHO Regional Office for Europe, 2002. Available at http://www.euro.who.int/_data/assets/pdf_file/0013/131521/E79235.pdf.

29. Prentice JC, Pizer SD. Delayed access to healthcare and mortality. Health services research. 2007;42(2):644-62.

30. Fraser Institute. Reducing Wait Times for Healthcare: What Canada Can Learn from Theory and International Experience / Steven Globerman (editor, 2013. Available at https://www.fraserinstitute.org/sites/default/files/reducing-wait-times-for-health-care.pdf. .

\section{Tables}

Table 1: Sociodemographic information of mothers who gave birth at University of Gondar teaching and referral hospital during September 2017 


\begin{tabular}{|c|c|c|}
\hline Sociodemographic variable & Frequency & Percent \\
\hline \multicolumn{3}{|l|}{ Place of residence } \\
\hline Urban & 274 & 68.0 \\
\hline Rural & 129 & 32.0 \\
\hline \multicolumn{3}{|l|}{ Age } \\
\hline $15-24$ years & 139 & 34.5 \\
\hline $25-34$ years & 207 & 51.4 \\
\hline 35 and above years & 57 & 14.1 \\
\hline \multicolumn{3}{|l|}{ Marital ststus } \\
\hline Engaged & 388 & 96.3 \\
\hline Not engaged & 15 & 3.7 \\
\hline \multicolumn{3}{|l|}{ Educational ststus } \\
\hline Do not attend formal education & 64 & 15.9 \\
\hline Secondary and below & 200 & 49.6 \\
\hline Diploma and above & 139 & 34.5 \\
\hline \multicolumn{3}{|l|}{ Occupation } \\
\hline Housewife & 95 & 23.6 \\
\hline Government employee & 198 & 49.1 \\
\hline Private employee & 35 & 8.7 \\
\hline Merchant & 43 & 10.7 \\
\hline Farmer & 25 & 6.2 \\
\hline Student & 7 & 1.7 \\
\hline \multicolumn{3}{|l|}{ Family size } \\
\hline$<=5$ & 318 & 78.9 \\
\hline$>5$ & 85 & 21.1 \\
\hline \multicolumn{3}{|l|}{ Number of births you gave } \\
\hline$<=5$ & 380 & 94.3 \\
\hline$>5$ & 23 & 5.7 \\
\hline
\end{tabular}

Table 2: ANC related services of mothers who gave birth at University of Gondar teaching and referral hospital during September 2017 


\begin{tabular}{lcc}
\hline ANC related information & Frequency & Percent \\
\hline Do you know about ANC? & 383 & 95 \\
$\quad$ Yes & 20 & 5 \\
$\quad$ No & & \\
Are you currently on ANC? & 372 & 92.3 \\
$\quad$ Yes & 31 & 7.7 \\
$\quad$ No & & \\
Where you follow ANC (n= 372)? & 153 & 41.1 \\
$\quad$ At a local health center & 219 & 58.9 \\
$\quad$ At Gondar university hospital & & \\
How many times you follow $(\mathbf{n}=\mathbf{3 7 2}) ?$ & 12 & 3.2 \\
$\quad$ Once & 150 & 40.3 \\
$\quad$ Two times & 55 & 14.8 \\
$\quad$ Three times & 155 & 41.7 \\
$\quad$ Four or more & & \\
How long does each visit lasts (n= 372) & 166 & 44.6 \\
$\quad$ <20 min & 206 & 55.4 \\
$\quad$ >20 min & & \\
\hline
\end{tabular}

Table 3: Delivery care services of mothers who gave birth at University of Gondar teaching and referral hospital during September 2017 


\begin{tabular}{|c|c|c|}
\hline Variable & Frequency & Percentage \\
\hline \multicolumn{3}{|c|}{ Place of delivery of previous children } \\
\hline No previous delivery & 29 & 7.2 \\
\hline At home & 78 & 19.4 \\
\hline At a health center & 66 & 16.4 \\
\hline At a hospital & 230 & 57.1 \\
\hline \multicolumn{3}{|c|}{ Mode of delivery of previous baby (374) } \\
\hline SVD & 318 & 85 \\
\hline CS & 56 & 15 \\
\hline \multicolumn{3}{|l|}{ If CS, how was the CS done? } \\
\hline Emergency & 42 & 75 \\
\hline Elective & 14 & 25 \\
\hline \multicolumn{3}{|c|}{ How do you come to this hospital? } \\
\hline Planned & 210 & 52.1 \\
\hline Referred & 193 & 47.9 \\
\hline \multicolumn{3}{|c|}{ How long do you wait to be seen by health a physician? } \\
\hline$<=10$ minutes & 215 & 53.3 \\
\hline$>10$ minutes & 188 & 46.7 \\
\hline \multicolumn{3}{|c|}{ How long does the labor last? } \\
\hline Up to 3 hours & 22 & 5.5 \\
\hline More than 3 hours & 381 & 94.5 \\
\hline \multicolumn{3}{|c|}{ Qualification of the physician who takes care of you } \\
\hline Doctor & 387 & 96.0 \\
\hline Midwife & 16 & 4.0 \\
\hline \multicolumn{3}{|c|}{ What is the outcome of the current pregnancy? } \\
\hline Alive & 380 & 94.3 \\
\hline Dead & 23 & 5.7 \\
\hline \multicolumn{3}{|c|}{ If the outcome is alive, what is the birth weight $(n=380) ?$} \\
\hline$<2500 \mathrm{gm}$ & 76 & 18.9 \\
\hline $2500-4000 \mathrm{gm}$ & 294 & 73 \\
\hline$>4000 \mathrm{gm}$ & 30 & 7.4 \\
\hline
\end{tabular}

Table 4: Factors associated with maternal satisfaction on delivery care services of mothers who gave birth at University of Gondar teaching and referral hospital during September 2017 


\begin{tabular}{|c|c|c|c|c|}
\hline \multirow[t]{2}{*}{ Variable } & \multicolumn{2}{|c|}{ Maternal satisfaction } & \multirow[t]{2}{*}{$\mathrm{COR}(95 \% \mathrm{CI})$} & \multirow[t]{2}{*}{ AOR(95\% CI) } \\
\hline & Satisfied & Dissatisfied & & \\
\hline \multicolumn{5}{|l|}{ Level of education } \\
\hline Do not attend formal education & 47 & 17 & 1 & \\
\hline Secondary and below & 132 & 68 & $0.70(0.38,1.32)$ & $0.42(0.20,0.90)^{*}$ \\
\hline Diploma and above & 85 & 54 & $0.57(0.30,1.09)$ & $0.29(0.13,0.66)^{* *}$ \\
\hline \multicolumn{5}{|l|}{ Currently on ANC follow-up } \\
\hline Yes & 249 & 123 & $2.16(1.03,4.51)$ & $4.47(1.77,11.27)^{* *}$ \\
\hline No & 15 & 16 & 1 & \\
\hline \multicolumn{5}{|l|}{ Waiting time } \\
\hline$<10$ minutes & 150 & 65 & $1.50(1.00,2.26)$ & $1.85(1.19,2.88)^{* *}$ \\
\hline$>10$ minutes & 114 & 74 & 1 & \\
\hline \multicolumn{5}{|l|}{ Qualification of care provider } \\
\hline Doctor & 251 & 136 & 1 & \\
\hline Midwifes & 13 & 3 & $2.35(0.66,8.38)$ & $2.60(0.71,9.58)$ \\
\hline \multicolumn{5}{|l|}{ Duration of labor } \\
\hline Up to 3 hours & 18 & 4 & $2.47(0.82,7.45)$ & $2.23(0.73,6.83)$ \\
\hline More than 3 hours & 246 & 135 & 1 & \\
\hline \multicolumn{5}{|l|}{ Pregnancy outcome } \\
\hline Alive & 252 & 128 & $1.81(0.78,4.20)$ & $1.90(0.76,4.74)$ \\
\hline Dead & 12 & 11 & 1 & \\
\hline
\end{tabular}

Note: $*$ p-value $<0.05 \mid * *$-value $<0.01 \mid$ Hosmer and Lemeshow Test $=0.140$

\section{Figures}




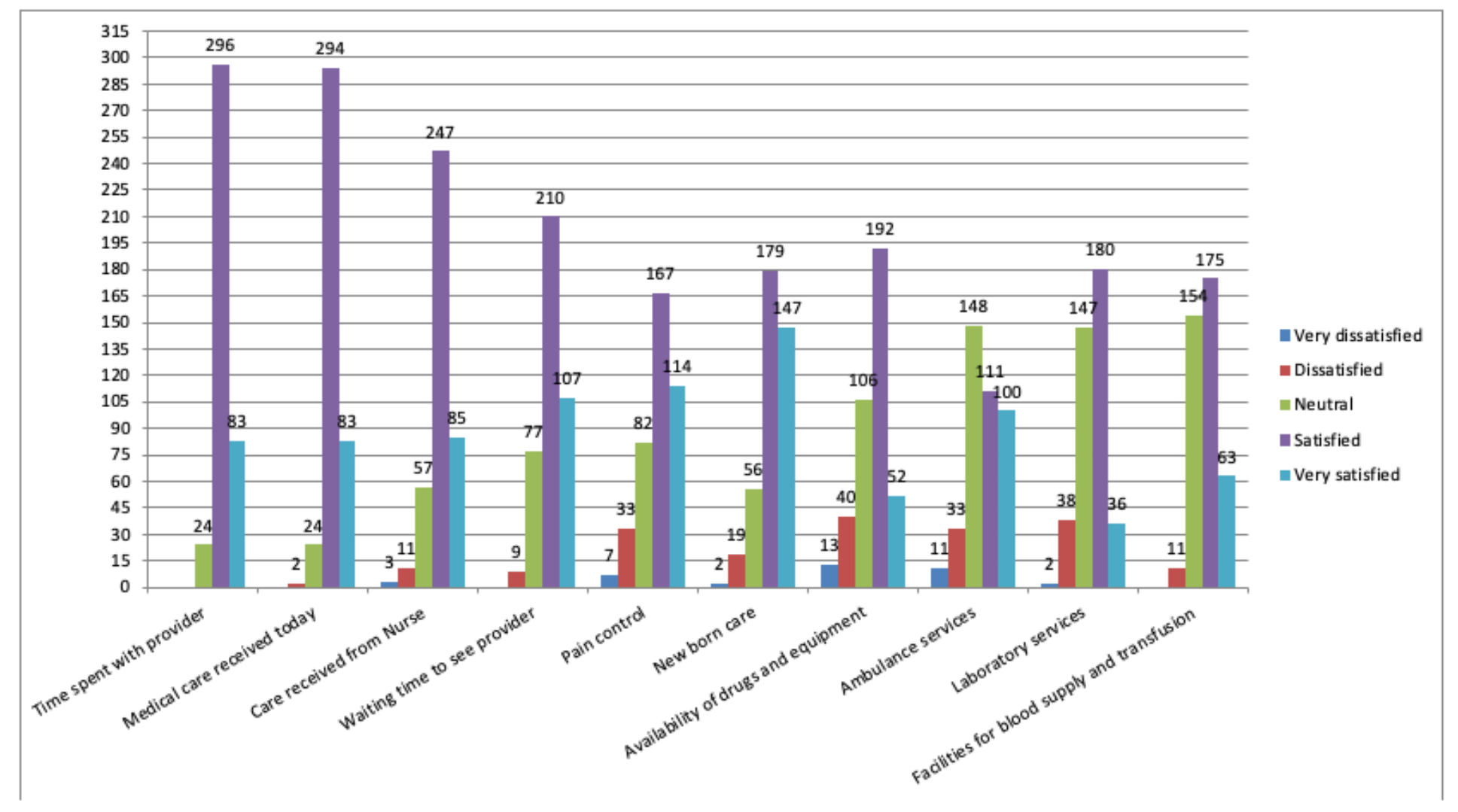

Figure 1

Level of satisfaction of mothers who gave birth at University of Gondar teaching and referral hospital during September 2017on healthcare services

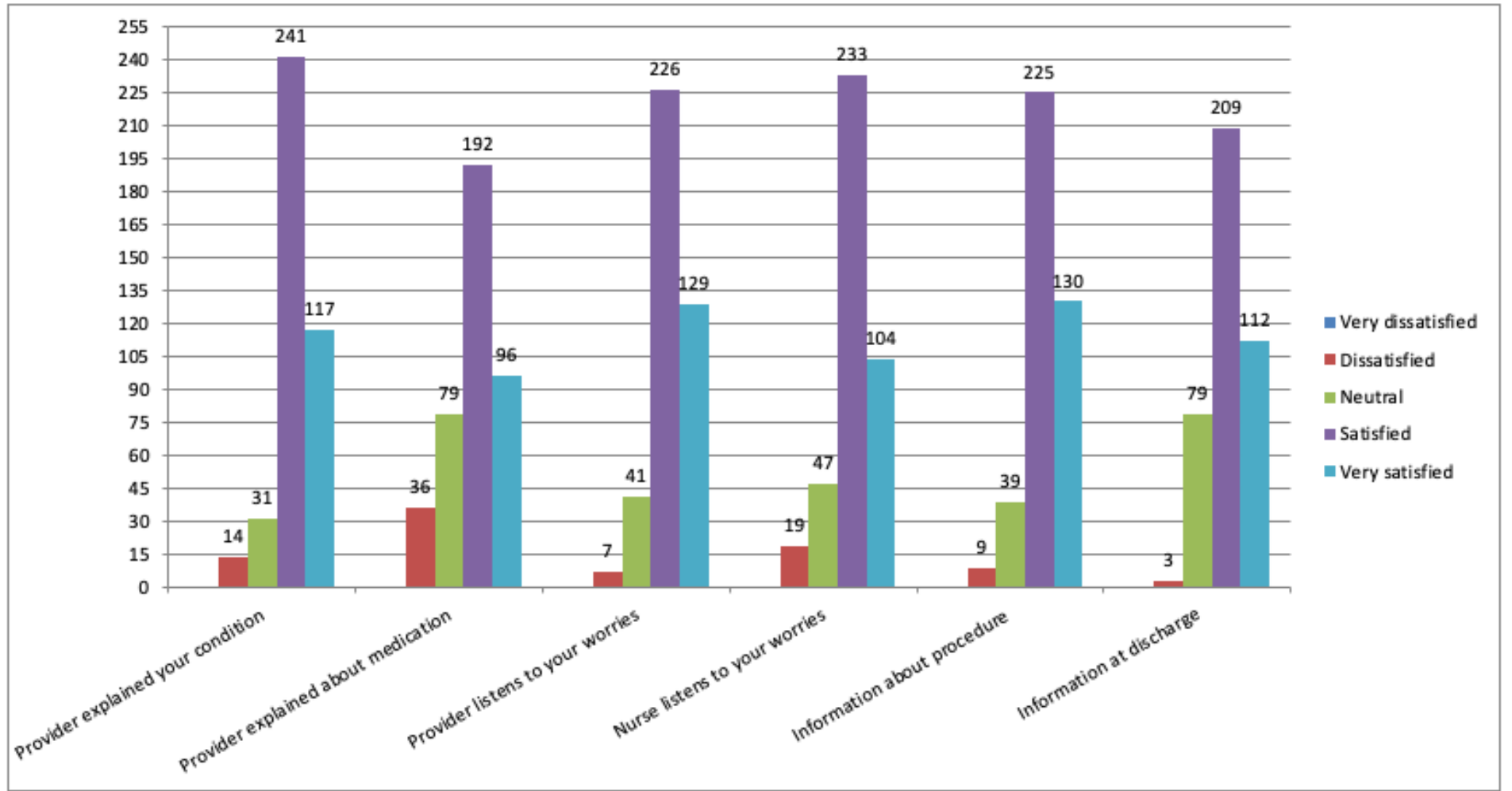


Figure 2

Level of satisfaction of mothers who gave birth at University of Gondar teaching and referral hospital during September 2017on health workers communication

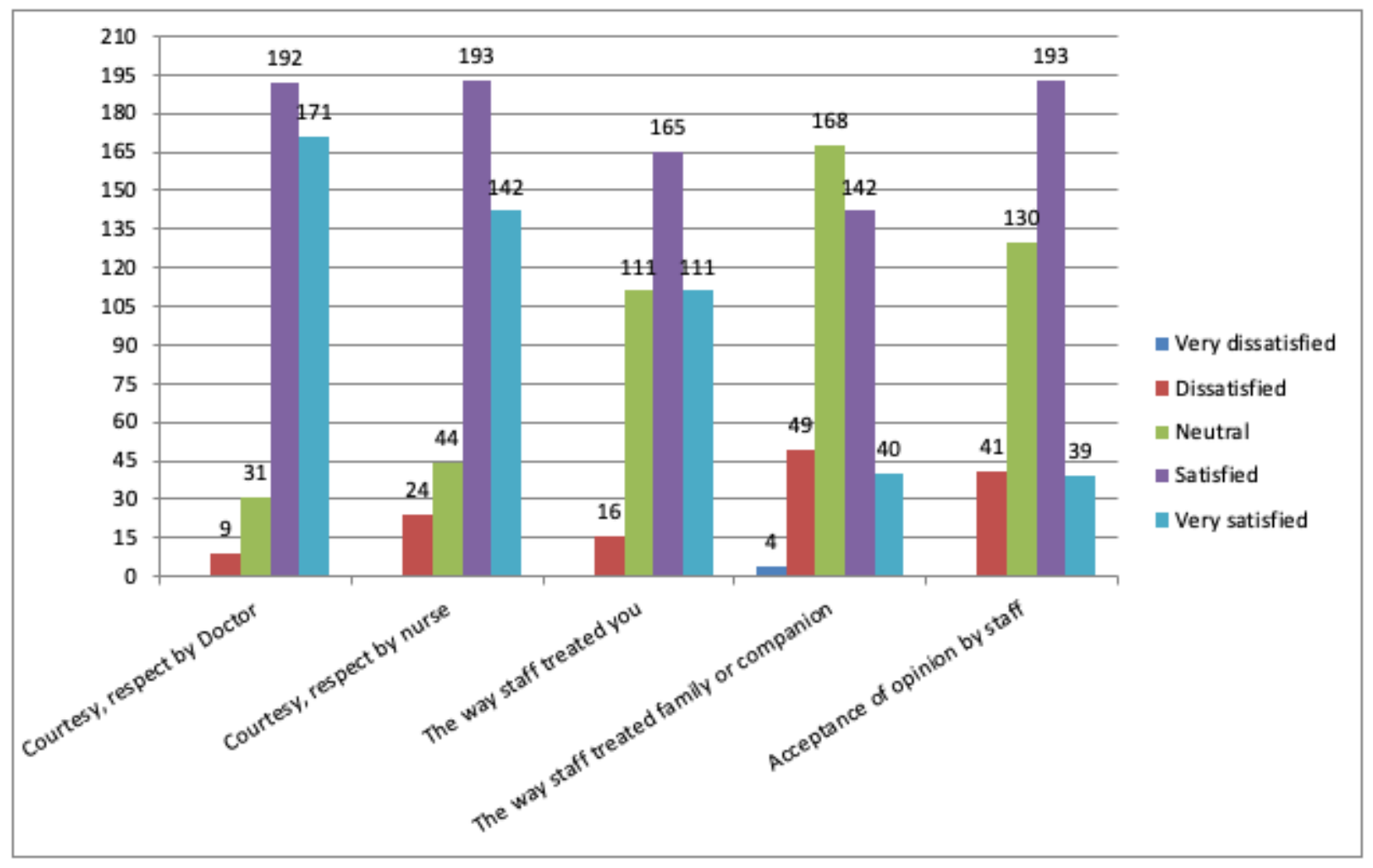

\section{Figure 3}

Level of satisfaction of mothers who gave birth at University of Gondar teaching and referral hospital during September 2017on health workers attitude 


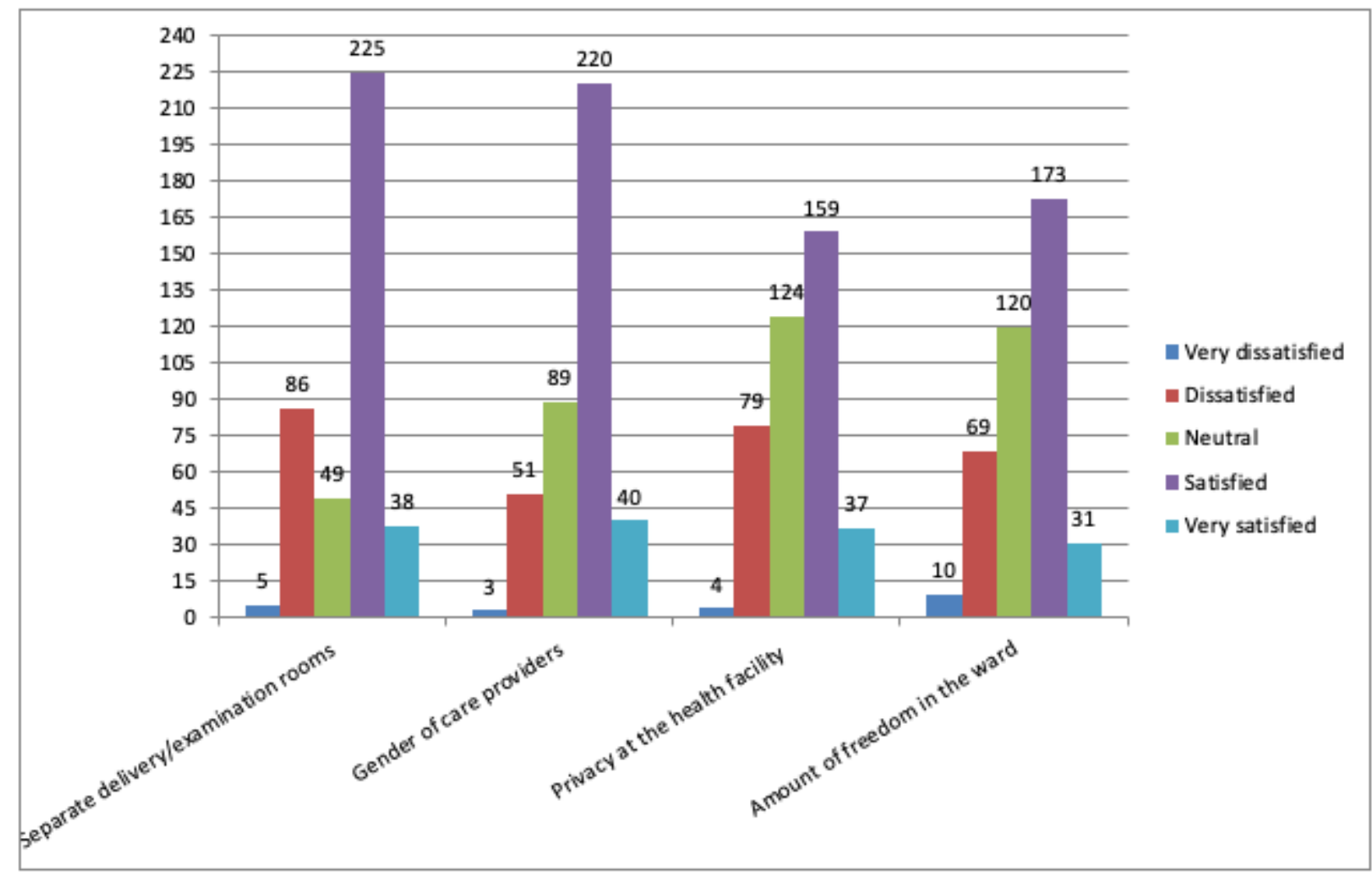

Figure 4

Level of satisfaction of mothers who gave birth at University of Gondar teaching and referral hospital during September 2017on privacy 


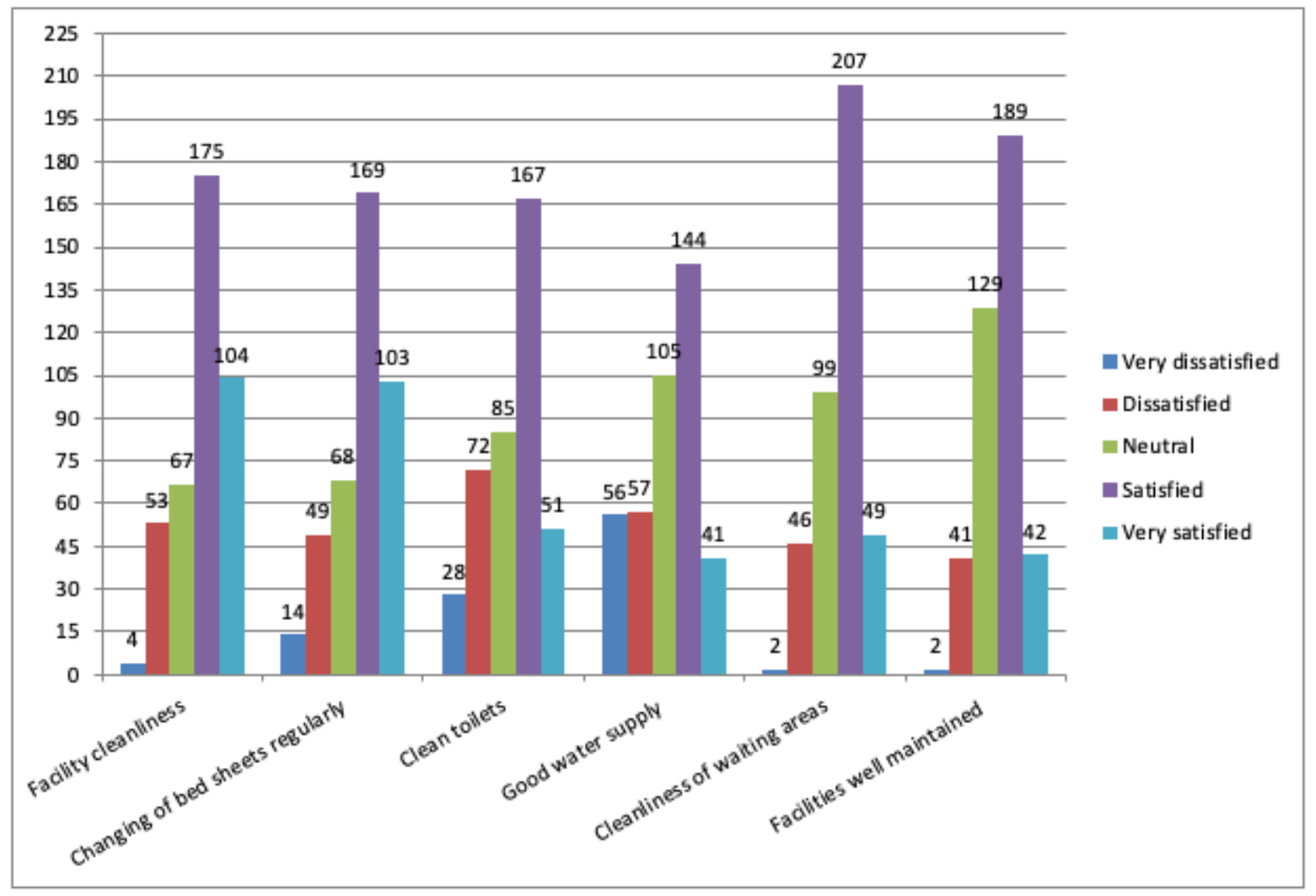

I

\section{Figure 5}

Level of satisfaction of mothers who gave birth at University of Gondar teaching and referral hospital during September 2017on sanitation 


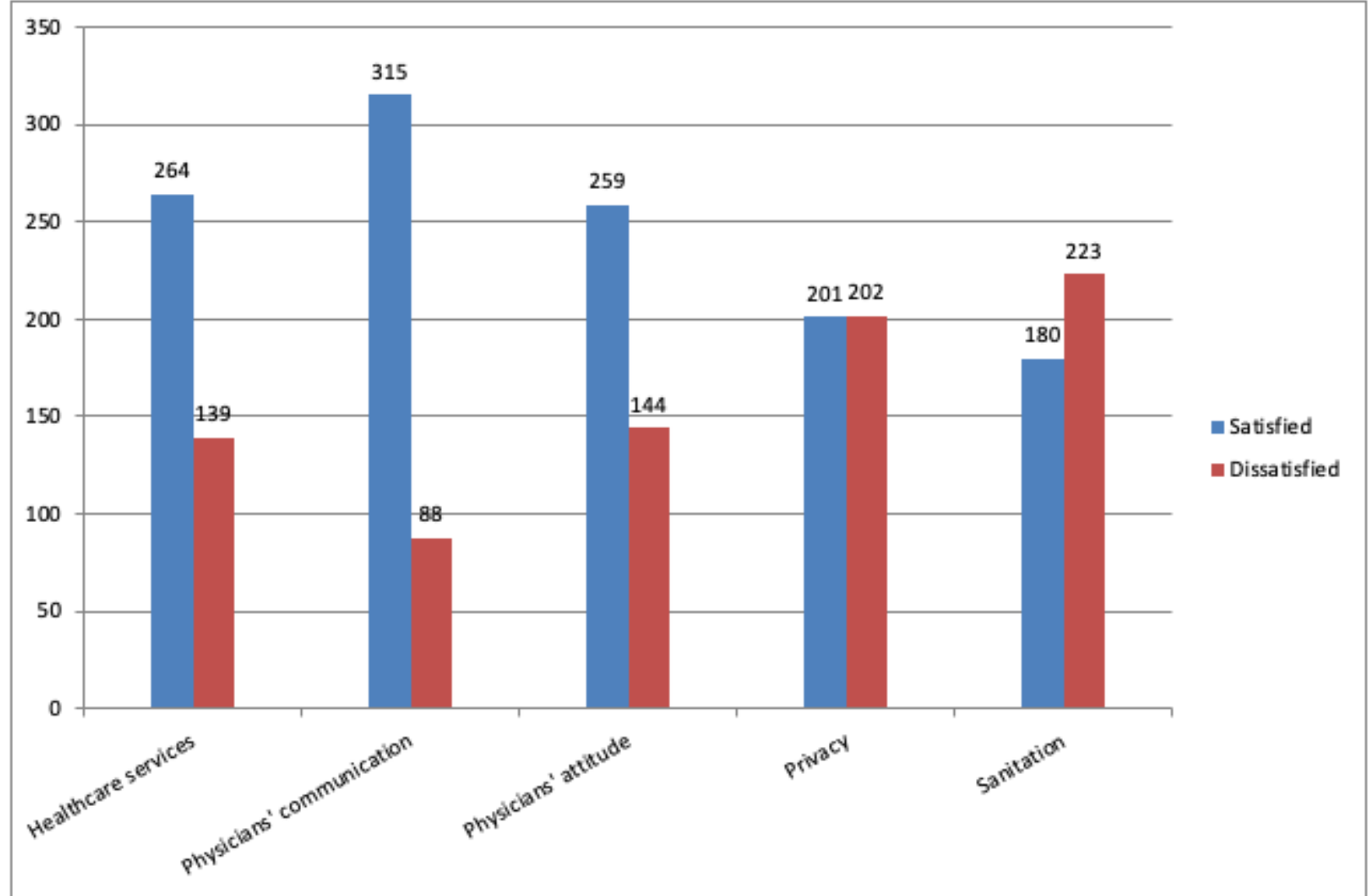

Figure 6

Level of satisfaction of mothers who gave birth at University of Gondar teaching and referral hospital during September 2017on healthcare services, physicians' communication, physicians' attitude, privacy and sanitation 